\title{
Transfusions and blood loss in total hip and knee arthroplasty: a prospective observational study
}

\author{
Malin S Carling ${ }^{1,2^{*}}$, Anders Jeppsson ${ }^{3,4}$, Bengt I Eriksson ${ }^{1,2}$ and Helena Brisby ${ }^{1,2}$
}

\begin{abstract}
Background: There is a high prevalence of blood product transfusions in orthopedic surgery. The reported prevalence of red blood cell transfusions in unselected patients undergoing hip or knee replacement varies between 21\% and $70 \%$. We determined current blood loss and transfusion prevalence in total hip and knee arthroplasty when tranexamic acid was used as a routine prophylaxis, and further investigated potential predictors for excessive blood loss and transfusion requirement.

Methods/materials: In total, 193 consecutive patients undergoing unilateral hip $(n=114)$ or knee arthroplasty $(n=79)$ were included in a prospective observational study. Estimated perioperative blood loss was calculated and transfusions of allogeneic blood products registered and related to patient characteristics and perioperative variables.

Results: Overall transfusion rate was 16\% (18\% in hip patients and 11\% in knee patients, $p=0.19)$. Median estimated blood loss was significantly higher in hip patients ( $984 \mathrm{vs} 789 \mathrm{~mL}, p<0.001$ ). Preoperative hemoglobin concentration was the only independent predictor of red blood cell transfusion in hip patients while low hemoglobin concentration, body mass index, and operation time were independent predictors for red blood cell transfusion in knee patients.

Conclusions: The prevalence of red blood cell transfusion was lower than previously reported in unselected total hip or knee arthroplasty patients. Routine use of tranexamic acid may have contributed. Low preoperative hemoglobin levels, low body mass index, and long operation increase the risk for red blood cell transfusion.
\end{abstract}

Keywords: Arthroplasty, Hemorrhage, Transfusion

\section{Introduction}

Orthopedic surgery, especially spine surgery and arthroplasty surgery, is associated with excessive bleeding and a high demand for blood transfusion [1,2]. In routine total hip arthroplasty and total knee arthroplasty, the prevalence of allogeneic red blood cell (RBC) transfusions has been reported to be between $21 \%$ and $70 \%$, with the majority of authors reporting figures in the middle of the range [1,3-5].

Allogeneic RBC transfusions are sometimes lifesaving, but also associated with a number of risks, including transfusion-related lung injury (TRALI), immunomodulation, and transmission of pathogens [6,7]. Studies have

\footnotetext{
* Correspondence: malin.carling@gmail.com

'Department of Orthopaedics, Sahlgrenska University Hospital, Gothenburg

SE 413 45, Sweden

${ }^{2}$ Department of Orthopaedics, Institute of Clinical Sciences, Sahlgrenska

Academy, University of Gothenburg, Gothenburg, Sweden

Full list of author information is available at the end of the article
}

also indicated that blood transfusion in itself may increase the risk of early and late morbidity and mortality $[8,9]$. Extensive perioperative bleeding is associated with an increased transfusion rate, as anticipated. However, other patient-related and surgery-associated factors, such as gender, preoperative hemoglobin levels, and operative technique are also predictive of transfusion requirement in different surgical settings $[2,10,11]$. There is sparse prospective data on risk factors for excessive bleeding and transfusion of blood products in total hip and knee arthroplasty.

In the present study, we assessed blood loss and transfusion requirements after elective primary total hip and knee arthroplasty when tranexamic acid was used as a routine prophylaxis, and we aimed at identifying clinically relevant predictors of excessive blood loss and transfusion requirements.

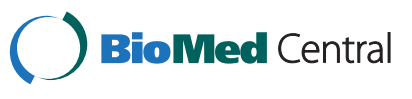




\section{Materials and methods Study design}

Patients with osteoarthritis undergoing total hip or knee arthroplasty were included in a prospective observational study where transfusions and blood loss were registered and related to perioperative characteristics.

\section{Patients and settings}

A total of 193 consecutive patients (mean age $67 \pm 11$ years, $49 \%$ women), with the diagnosis osteoarthritis undergoing unilateral primary hip $(n=114)$ or knee $(n=79)$ arthroplasty at two centers (Sahlgrenska University Hospital and Kungälv Hospital), were included in the study between October 2009 and January 2011. Exclusion criteria were known liver disease or coagulation disorder.

\section{Ethics, consent, and permissions}

The Regional Ethical Review Board in Gothenburg approved the study (date of approval 11 September 2009, reference number 072-08). All patients gave informed written consent before inclusion in the study.

\section{Clinical management}

Spinal anesthesia was used in 160 (83\%) of the patients (95 hip, 65 knee) and general anesthesia in the remaining patients. Dabigatran was used as thrombosis prophylaxis in 179 patients (104 hip, 75 knee) while 14 patients received low molecular weight heparin (LMWH) (15 hip, 4 knee). The first dose of dabigatran was administered $1-4 \mathrm{~h}$ after surgery while the first dose of LMWH was administered in the evening before surgery. All patients received tranexamic acid (Cyklokapron; Pfizer, Sollentuna, Sweden), $10 \mathrm{mg} / \mathrm{kg}$ body weight; for hip patients, one dose after start of anesthesia and one dose $3 \mathrm{~h}$ later; for knee patients, one dose 10-15 min before release of the tourniquet and one dose $3 \mathrm{~h}$ later, according to the local routine.

All patients in the knee group received cemented prostheses and they were operated with a tourniquet. In the hip group, 55 patients received cemented prostheses, 25 received uncemented prostheses, 9 received hybrid arthroplasties (uncemented acetabular component and cemented femoral component), and 10 received reverse hybrid arthroplasty (cemented acetabular component and uncemented femoral component). None of the knee or hip patients had wound drainage postoperatively.

The following baseline variables were recorded: age; gender; BMI; medication prior to surgery, including the use of acetylsalicylic acid (ASA), nonsteroidal antiinflammatory drugs (NSAIDs), or selective serotonin receptor inhibitors (SSRIs); type of surgery; and thrombosis prophylaxis. Patients on ASA or NSAIDs were urged to discontinue these medications 3 days before surgery. Medication with potent platelet inhibitors, such as clopidogrel, were stopped at least 1 week before surgery. Blood samples from a peripheral vein for hemoglobin $(\mathrm{Hb})$, platelet count, activated partial thromboplastin time (aPTT), and prothrombin time (PT) analyses were obtained $<24 \mathrm{~h}$ before surgery. Hemoglobin level was also measured $24-48 \mathrm{~h}$ postoperatively in order to calculate blood loss.

The following perioperative variables were recorded: duration of operation, bleeding during surgery (intraoperatively), transfusion requirements intraoperatively, and postoperatively until discharge or until reoperation and autologous transfusion of wound blood after cell saver processing. Intraoperative bleeding was calculated from blood retrieved from wound suction plus the estimated amount of blood in the swabs.

\section{Analyses}

Whole blood samples for determination of $\mathrm{Hb}$ and platelet count analyses were collected in K2 EDTA plastic tubes (1.8 g/L EDTA; BD Vacutainer, Plymouth, UK). For PT and APTT analyses, blood samples were collected in citrated plastic tubes $(2.7 \mathrm{~mL} 0.129 \mathrm{mmol} / \mathrm{L}$ sodium citrate; BD Vacutainer, Plymouth, UK). Hb, platelet count, aPTT, and PT were analyzed with clinical standard methods at the accredited local hospital laboratories. PT is reported as the international normalized ratio (INR); reference value: $<1.2$. The reference value for APTT is $30-42 \mathrm{~s}$.

\section{Definitions and formulae}

Estimated blood loss (EBL) was calculated based on the drop in $\mathrm{Hb}$ between the preoperative measurements and the measurements $24-48 \mathrm{~h}$ postoperatively according to a formula developed by Brecher [12]. Only intraoperative transfusions are included in the calculation since none of the patients received postoperative transfusion in the interval between end of surgery and before the blood sample taken 24-48 h postoperatively for $\mathrm{Hb}$ determination. The formula used was as follows: EBL = (("estimated blood volume (EBV)" $\times$ "hematocrit preoperatively" $E B V \times$ "hematocrit postoperatively") + ("intraoperative RBC transfusion" $\times 200+$ "intraoperative Cellsaver transfusion" $\times 0.55)$ ) / 0.35 [12].

For EBV, the formula is as follows: EBV $=(0.0235 \times$ height in $\mathrm{cm}^{\wedge} 0.42246 \times$ weight in $\left.\mathrm{kg}^{\wedge} 0.51456\right) \times k$, where $k=2,430$ for women and 2,530 for men. Patients in the upper 75th percentile of EBL/ $\mathrm{kg}$ in the hip and knee group, respectively, were defined as excessive bleeders while all other patients were considered to be nonexcessive bleeders.

The study population was also divided into a transfusion group with those patients who received allogeneic RBC transfusions until discharge from hospital and a notransfusion group with the patients who did not receive 
any allogeneic RBC transfusion. No pre-specified transfusion criteria were used during the study period, i.e., transfusions were prescribed at the discretion of the attending physician.

\section{Statistics}

Continuous variables were compared with Student $t$-test or Mann-Whitney $U$ test, and categorical variables were compared with Chi-square test. In the statistical analysis, PT was considered a continuous variable. Statistical significance was defined as a $p$ value of $<0.05$. Statistical models for identification of predictors of blood loss and transfusion were made with logistic regression analysis. For multiple regression analysis, stepwise logistic regression analysis was used. The following variables were included in the analysis: age; gender; BMI; use of NSAIDs, ASA, or SSRI before surgery; type of anesthesia; operation time; and preoperative $\mathrm{Hb}$, platelet count, PT, and aPTT. For analyses of RBC transfusions, weight was also included. For statistical calculations, IBM SPSS 20.0 software was used.

\section{Results}

General

All patients survived the perioperative period, and there were no major complications except one hip patient that was re-operated because of inappropriate stem placement, and one knee patient was re-operated because of early, deep infection. There were no significant differences in any of the registered parameters between the two study hospitals. Patients in the knee group had a significantly higher BMI than patients in the hip group $(p<0.001)$. Operation time was significantly longer for the hip group than for the knee group $(p=0.004)$. For patient characteristics and perioperative variables (Table 1).

\section{Bleeding and estimated blood loss}

Observed median intraoperative bleeding for hip patients was $450 \mathrm{~mL}$ (range 150-3,000) and for knee patients $0 \mathrm{~mL}$ (range 0-600). The median EBL was 984 and $789 \mathrm{~mL}$ for hip and knee patients, respectively. There was a significant difference between observed perioperative bleeding and EBL for both hip and knee patients (Figure 1). There was a significant difference in median EBL $(p=0.001)$ and EBL/ $\mathrm{kg}(p<0.001)$ between the hip group and the knee group (Table 1).

In hip patients, a univariate logistic regression analysis showed that female gender, low BMI, and long operation time were associated with $\mathrm{EBL} / \mathrm{kg}>75$ th percentile $(>17.1 \mathrm{~mL} / \mathrm{kg}$ ) (Table 2). In the multiple regression analysis, female gender (odds ratio (OR) 3.91 (95\% confidence interval 1.41-10.88) per $\mathrm{kg}, p=0.009)$, low BMI (OR $0.82(0.71-0.94)$ per unit, $p=0.005$ ), and long
Table 1 Patient characteristics

\begin{tabular}{|c|c|c|c|}
\hline & $\begin{array}{l}\text { Hip } \\
\text { arthroplasty } \\
n=114\end{array}$ & $\begin{array}{l}\text { Knee } \\
\text { arthroplasty } \\
n=79\end{array}$ & $\begin{array}{l}p \text { value } \\
\text { (hip vs. knee }\end{array}$ \\
\hline Male gender & $62(54 \%)$ & $32(41 \%)$ & 0.058 \\
\hline \multicolumn{4}{|l|}{ Preop medication } \\
\hline NSAID & $30(26 \%)$ & $16(20 \%)$ & 0.33 \\
\hline $\begin{array}{l}\text { Acetylsalicylic } \\
\text { acid }\end{array}$ & $18(16 \%)$ & $18(23 \%)$ & 0.22 \\
\hline SSRI & $10(9 \%)$ & $9(11 \%)$ & 0.55 \\
\hline \multicolumn{4}{|l|}{ Thromboprophylaxis } \\
\hline Dabigatran & 104 (91\%) & 75 (95\%) & 0.33 \\
\hline LMWH & $10(9 \%)$ & $4(5 \%)$ & \\
\hline \multicolumn{4}{|l|}{ Anesthesia } \\
\hline Spinal & 95 (83\%) & 65 (82\%) & 0.85 \\
\hline General & 19 (17\%) & $14(18 \%)$ & \\
\hline BMI $\left(\mathrm{kg} / \mathrm{m}^{2}\right)$ & $27 \pm 4.1(17-40)$ & $30 \pm 4.5(22-49)$ & $<0.001$ \\
\hline Age (years) & $66 \pm 12$ & $69 \pm 10$ & 0.086 \\
\hline Hemoglobin $(g / L)$ & $136 \pm 13$ & $133 \pm 12$ & 0.24 \\
\hline Platelet count $\left(10^{9} / \mathrm{L}\right)$ & $283 \pm 65$ & $280 \pm 72$ & 0.81 \\
\hline PT (INR) & $1.0 \pm 0.1$ & $1.0 \pm 0.1$ & 0.77 \\
\hline aPTT (s) & $34 \pm 3.8$ & $33 \pm 3.3$ & 0.57 \\
\hline $\begin{array}{l}\text { Operation time } \\
\text { (min) }\end{array}$ & $125 \pm 28$ & $113 \pm 28$ & 0.004 \\
\hline RBC transfusion & $21(18 \%)$ & $9(11 \%)$ & 0.18 \\
\hline $\begin{array}{l}\text { RBC transfusion } \\
\text { (units) }\end{array}$ & $0(0-4)$ & $0(0-3)$ & 0.22 \\
\hline EBL $(m L)$ & $984(0-4571)$ & $789(0-1927)$ & 0.001 \\
\hline $\mathrm{EBL} / \mathbf{k g}(\mathbf{m L} / \mathbf{k g})$ & $12(0-33)$ & $9(0-23)$ & $<0.001$ \\
\hline Cellsaver (mL) & $0(0-1200)$ & 0 & 0.007 \\
\hline
\end{tabular}

Abbreviations: aPTT activated partial thromboplastin time, BMI body mass index, EBL estimated blood loss, LMWH low molecular weight heparin, NSAID nonsteroidal anti-inflammatory drugs, $P T$ prothrombine time, RBC transfusion red blood cell transfusion, SSRI selective seretonine receptor inhibitor. Mean and standard deviation, median and range, or number and percentage.

operation time (OR $1.03(1.01-1.05)$ per min, $p=0.04)$ increased the risk of excessive blood loss.

In knee patients, low BMI and high preoperative $\mathrm{Hb}$ were univariately associated with $\mathrm{EBL} / \mathrm{kg}>75$ th percentile $(>12.7 \mathrm{~mL} / \mathrm{kg})$ (Table 3). In the multiple regression analysis, low BMI (OR $0.77(0.64-0.93)$ per unit, $p=0.006$ ) and high preoperative $\mathrm{Hb}$ (OR 1.11 (1.04-1.17) per g/L, $p=0.001)$ increased the risk of excessive bleeding.

\section{Transfusions}

Ten patients, all in the hip group, received intraoperative re-transfusion of cell saver processed wound blood. The median re-transfused volume was $300 \mathrm{~mL}$ (range 150$1,200 \mathrm{~mL}$ ). None of these patients received allogeneic $\mathrm{RBC}$ transfusion. 


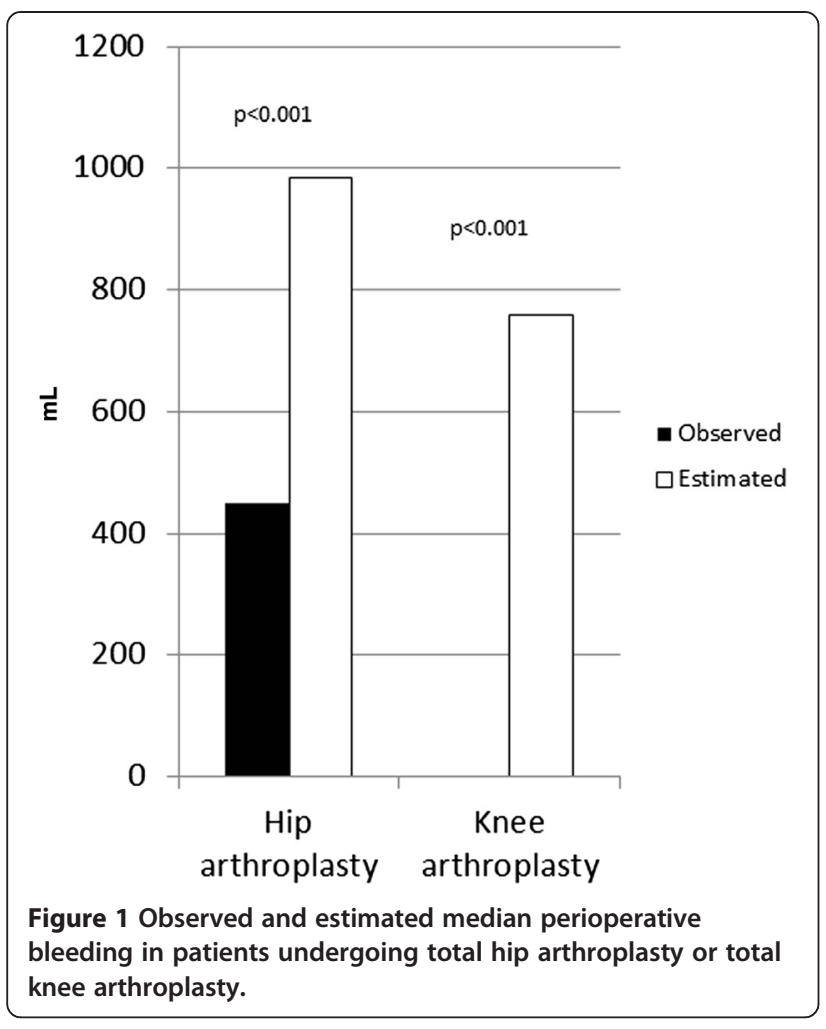

In total, 30 patients (16\%) received allogeneic blood transfusions during their hospital stay, 21 in the hip group and 9 in the knee group. There was no statistically significant difference in transfusion prevalence between the hip group and the knee group (18\% vs. $11 \%, p=0.19)$. One patient received transfusion with fresh frozen plasma intraoperatively. Thirteen patients, all in the hip group, received allogeneic RBC transfusion intraoperatively, while none of the knee patients received intraoperative transfusion. Eighteen patients received allogeneic RBC transfusion more than $24 \mathrm{~h}$ postoperatively, 8 in the hip group and 10 in the knee group. One patient in the hip group received both intraoperative and postoperative allogeneic RBC transfusion.

In hip patients, low preoperative $\mathrm{Hb}$, high age, female gender, and large EBL $/ \mathrm{kg}$ were univariately associated with perioperative allogeneic RBC transfusion (Table 2). In multiple regression analyses, preoperative $\mathrm{Hb}$ was the only factor significantly predictive of allogeneic RBC transfusion (OR 0.87 (0.82-0.93) per g/L, $p<0.001)$.

In knee patients, low preoperative $\mathrm{Hb}$, low $\mathrm{BMI}$, long aPTT, and long operation time were univariately associated with allogeneic RBC transfusion (Table 3). In multiple regression analysis, low BMI (OR 0.71 (0.51-0.98) per unit, $p=0.034$ ), low preoperative $\mathrm{Hb}$ (OR 0.71 (0.51-0.98) per $\mathrm{g} / \mathrm{L}, p=0.015)$, and long operation time (OR 1.04 (1.00-1.07) per minute, $p=0.036$ ),increased the risk of $\mathrm{RBC}$ transfusion.

\section{Discussion}

The main findings in the present study were as follows: (1) The rate of transfusion (16\%) was lower than previously reported in unselected patients undergoing total primary hip and knee arthroplasty. (2) The lower transfusion rate was not accompanied with any indications of increased complication rate. (3) Preoperative hemoglobin concentration, body mass index, and operating time were

Table 2 Univariate risk factor analysis in total hip arthroplasty patients for excessive bleeding and transfusions

\begin{tabular}{|c|c|c|c|c|c|c|}
\hline & \multicolumn{3}{|c|}{ Excessive bleeding (EBL/kg >17.1 mL/kg) } & \multicolumn{3}{|c|}{ Allogeneic RBC transfusion } \\
\hline & OR & $95 \% \mathrm{Cl}$ & $p$ value & OR & $95 \% \mathrm{Cl}$ & $p$ value \\
\hline Age (years) & 1.00 & $0.99-1.07$ & 0.11 & 1.05 & $1.01-1.10$ & 0.022 \\
\hline $\operatorname{Sex}(F)$ & 3.39 & $1.37-8.38$ & 0.008 & 7.04 & $2.19-22.63$ & 0.001 \\
\hline BMI $\left(\mathrm{kg} / \mathrm{m}^{2}\right)$ & 0.83 & $0.73-0.95$ & 0.006 & 0.90 & $0.79-1.03$ & 0.13 \\
\hline Weight (kg) & 0.92 & $0.89-0.96$ & $<0.001$ & 0.94 & $0.91-0.98$ & 0.003 \\
\hline NSAID (No) & 1.42 & $0.51-3.93$ & 0.50 & 0.66 & $0.24-1.83$ & 0.42 \\
\hline ASA (No) & 1.17 & $0.35-3.89$ & 0.80 & 0.75 & $0.22-2.57$ & 0.65 \\
\hline SSRI (No) & 0.45 & $0.12-1.73$ & 0.24 & 0.29 & $0.08-1.15$ & 0.079 \\
\hline Hemoglobin (g/L) & 0.97 & $0.94-1.01$ & 0.12 & 0.87 & $0.82-0.93$ & $<0.001$ \\
\hline Platelet count $\left(10^{9} / \mathrm{L}\right)$ & 1.01 & $1.00-1.01$ & 0.17 & 1.00 & $1.00-1.01$ & 0.52 \\
\hline PT (INR) & 0.76 & $0.001-70.9$ & 0.90 & 0.03 & $0.00-7.71$ & 0.21 \\
\hline aPTT (s) & 1.01 & $0.90-1.13$ & 0.87 & 1.05 & $0.93-1.17$ & 0.45 \\
\hline Operation time (minutes) & 1.02 & $1.00-1.04$ & 0.017 & 1.02 & $1.00-1.03$ & 0.065 \\
\hline Anesthesia (spinal) & 0.89 & $0.29-2.75$ & 0.85 & 0.82 & $0.24-2.77$ & 0.75 \\
\hline EBL/kg & & n.a. & & 1.17 & $1.09-1.26$ & $<0.001$ \\
\hline
\end{tabular}

Abbreviations: aPTT activated partial thromboplastin time, BMI body mass index, EBL estimated blood loss, LMWH low molecular weight heparin, NSAID nonsteroidal anti-inflammatory drugs, $P T$ prothrombine time, $R B C$ transfusion red blood cell transfusion, SSRI selective seretonine receptor inhibitor. 
Table 3 Univariate risk factor analysis in total knee arthroplasty patients for excessive bleeding and transfusions

\begin{tabular}{|c|c|c|c|c|c|c|}
\hline & \multicolumn{3}{|c|}{ Excessive bleeding (EBL/kg >12.7 mL/kg) } & \multicolumn{3}{|c|}{ Allogeneic RBC transfusion } \\
\hline & OR & $95 \% \mathrm{Cl}$ & $p$ value & OR & $95 \% \mathrm{Cl}$ & $p$ value \\
\hline Age (years) & 1.02 & $0.97-1.08$ & 0.45 & 0.99 & $0.92-1.06$ & 0.79 \\
\hline $\operatorname{Sex}(F)$ & 0.69 & $0.24-1.95$ & 0.49 & 0.29 & $0.068-1.28$ & 0.10 \\
\hline BMI $\left(\mathrm{kg} / \mathrm{m}^{2}\right)$ & 0.81 & $0.69-0.95$ & 0.010 & 0.78 & $0.62-0.98$ & 0.034 \\
\hline Weight (kg) & 0.96 & $0.92-1.0$ & 0.046 & 0.97 & $0.92-1.02$ & 0.26 \\
\hline NSAID (No) & 0.94 & $0.26-3.34$ & 0.92 & 0.88 & $0.16-4.68$ & 0.88 \\
\hline ASA (No) & 1.14 & $0.32-4.0$ & 0.84 & 2.57 & $0.3-22.02$ & 0.39 \\
\hline SSRI (No) & 1.12 & $0.21-5.93$ & 0.89 & 1.03 & $0.11-9.37$ & 0.98 \\
\hline Hemoglobin (g/L) & 1.09 & $1.03-1.16$ & 0.001 & 0.91 & $0.84-0.97$ & 0.007 \\
\hline Platelet count $\left(10^{9} / \mathrm{L}\right)$ & 1.0 & $0.99-1.01$ & 0.56 & 1.001 & $0.99-1.01$ & 0.88 \\
\hline PT (INR) & 0.001 & $0.00-1.03$ & 0.051 & 0.036 & $0-220.4$ & 0.46 \\
\hline aPTT (s) & 0.91 & $0.78-1.07$ & 0.26 & 1.34 & $1.03-1.74$ & 0.028 \\
\hline Operation time (minutes) & 1.00 & $0.98-1.02$ & 0.87 & 1.03 & $1.00-1.06$ & 0.034 \\
\hline Anesthesia (spinal) & 2.12 & $0.43-10.48$ & 0.35 & 0.72 & $0.13-3.92$ & 0.71 \\
\hline $\mathrm{EBL} / \mathrm{kg}$ & & n.a. & & 1.020 & $0.88-1.18$ & 0.795 \\
\hline
\end{tabular}

Abbreviations: aPTT activated partial thromboplastin time, $A S A$ acetyl salicylic acid, BMI body mass index, EBL estimated blood loss, $L M W H$ low molecular weight heparin, NSAID nonsteroidal anti-inflammatory drugs, PT prothrombine time, RBC transfusion red blood cell transfusion, SSRI selective seretonine receptor inhibitor.

the most important risk factors for excessive blood loss and transfusion.

In the present study, the perioperative estimated blood loss volume was greater for hip arthroplasty patients than for knee arthroplasty patients (Table 2), which contrasts with the results of a previous study [13]. However, the difference was limited (median difference $195 \mathrm{~mL}$, or $3.1 \mathrm{~mL} / \mathrm{kg}$ ) and may not be clinically relevant. The results also show that even though knee arthroplasty is performed with a tourniquet and the intraoperative bleeding is minimal, the patients have a significant amount of perioperative blood loss. Median EBL in knee patients was $790 \mathrm{~mL}$ (range 0-1,927) in the present study, and even though this is an estimated volume, it reflects a blood loss that may affect the patients. Hidden blood loss after knee arthroplasty with a tourniquet is a known concern, and several studies have shown that there is no difference in total perioperative bleeding after knee arthroplasty with or without a tourniquet $[14,15]$. In the hip patients, in the present study, also a relatively large hidden blood loss was calculated and may also be a concern. This is in accordance with the findings in a study by Liu et al. [16].

Low BMI was associated with an increased risk of excessive blood loss. This is in accordance with findings from heart surgery, where low BMI has been shown to be a risk for reoperation because of excessive bleeding [17]. For hip and knee arthroplasty, the results vary in different studies. In studies by Prasad et al. and Hrnack et al., BMI was not found to be associated with blood loss in neither hip nor knee patients [18,19]. For hip arthroplasty patients, Bowditch et al. reported an increased risk of bleeding in obese patients [20]. The contrasting findings in different studies regarding the association between BMI and bleeding may be at least partially explained by the fact that some studies have used bleeding volume per $s e$ and others have used bleeding per $\mathrm{kg}$ in the calculations. The finding of increased risk of bleeding with longer operation time may be a direct effect of time, if a relatively constant amount of bleeding per time unit can be expected. However, it may also be the other way around; a higher degree of intraoperative bleeding may extend the surgical time. With the present data, we cannot distinguish between these mechanisms.

In contrast to the blood loss results, there was no statistically significant difference in transfusion requirements between hip and knee patients $(p=0.19)$. However, there was a numerical difference with higher transfusion requirements in hip patients (18\% vs. $11 \%$ ), and the possibility of statistical type-II error cannot be excluded. The total $\mathrm{RBC}$ transfusion requirements for unselected hip and knee arthroplasty patients was $16 \%, 30$ patients out of 194 , which is markedly lower than in most previous publications [2,4,21-23]. Borghi et al. reported allogeneic RBC transfusion requirements of only $10 \%$ for total hip and knee arthroplasty patients [24]. However, that study and other studies reporting low transfusion rates have been focused studies, investigating the use of a new transfusion protocol $[25,26]$ or the use of autologous transfusion programs [27]. It is difficult to compare studies since, besides differences in study design and study populations, some investigators only included postoperative transfusions but not intraoperative ones in their analysis. In the present study, we report the total number of perioperative 
transfusion. No specific transfusion protocol or transfusion triggers were used, and a large number of physicians were involved in the care of these patients.

In accordance to previous studies [2,28-30], we found that a low preoperative $\mathrm{Hb}$ was a significant risk factor for receiving allogeneic $\mathrm{RBC}$ transfusions. This is not surprising, since a low $\mathrm{Hb}$ is a known transfusion trigger. Studies on anemic patients undergoing major orthopedic surgery have shown that optimizing the patients' $\mathrm{Hb}$ preoperatively with erythropoietin and iron treatment may reduce transfusion rates [31].

A number of different measures can be taken to minimize the need for allogeneic transfusions, including transfusions of predonated autologous blood, cell salvage systems, and administration of pro-haemostatic drugs. It has been demonstrated that predonated autologous blood transfusions are cost-effective and reduce allogeneic blood transfusions in selected patient groups [32]. The use of autotransfusion, or cell salvage, reduces the number of intraoperative allogeneic RBC transfusions [33]. This was also noted in the present study where none of the ten hip patients who received autotransfusion of cell-salvaged blood did require transfusion of allogeneic blood. The introduction of new transfusion protocols and policies may also affect the rates of transfusion [34].

Tranexamic acid is commonly used in hip and knee arthroplasty surgery in Sweden. The use of tranexamic acid and other anti-fibrinolytic substances is well-studied and known to significantly decrease the number of transfusions in cardiac and orthopedic surgery [35]. Our study population received tranexamic acid according to hospital guidelines, and this may have contributed to low bleeding volumes and low transfusion rates.

One limitation of the present study was the restricted number of patients included, which did not allow further subgroup analysis. The lack of a specific transfusion protocol or transfusion triggers as well as the involvement of a large number of physicians involved in the care of these patients could also possibly have influenced the results. However, one of the strengths of this study is that the investigation was performed in consecutive patients in an everyday clinical setting without selection bias.

\section{Conclusions}

This study showed that an unselected group of patients undergoing elective primary total hip or knee arthroplasty in an everyday clinical setting had a lower risk of receiving a blood transfusion as compared to many reports in the literature. Predictors for receiving allogeneic transfusion were a low preoperative $\mathrm{Hb}$ and a low BMI. With increased awareness in the organization and structured transfusion programs, the transfusion rate may be possible to reduce further.

\section{Competing interests}

The authors declare that they have no competing interests.

\section{Authors' contributions}

MSC, HB, and AJ designed the study. MSC recruited patients, analyzed the data, and wrote the first draft of the manuscript. $H B, B I E$, and $A J$ participated in data analysis and interpretation and revision of the manuscript. All authors have approved the final version of the paper.

\section{Acknowledgements}

The study was supported by grants from the Health \& Medical Care Committee of the Regional Executive Board, Region Västra Götaland and research grant under the ALF agreement, Västra Götaland to HB and from Gothenburg Medical Society to MSC. The sponsors of the study had no influence on the analysis and interpretation of data, on the writing of the report, or on the decision to submit the paper for publication.

\section{Author details}

'Department of Orthopaedics, Sahlgrenska University Hospital, Gothenburg SE 413 45, Sweden. ${ }^{2}$ Department of Orthopaedics, Institute of Clinical Sciences, Sahlgrenska Academy, University of Gothenburg, Gothenburg, Sweden. ${ }^{3}$ Department of Cardiothoracic Surgery, Sahlgrenska University Hospital, Gothenburg, Sweden. ${ }^{4}$ Department of Molecular and Clinical Medicine, Institute of Medicine, Sahlgrenska Academy, University of Gothenburg, Gothenburg, Sweden.

Received: 28 December 2014 Accepted: 16 March 2015 Published online: 28 March 2015

\section{References}

1. Rosencher N, Kerkkamp HE, Macheras G, Munuera LM, Menichella G, Barton DM, et al. Orthopedic Surgery Transfusion Hemoglobin European Overview (OSTHEO) study: blood management in elective knee and hip arthroplasty in Europe. Transfusion. 2003;43:459-69.

2. Vuille-Lessard É, Boudreault D, Girard F, Ruel M, Chagnon M, Hardy J-F. Red blood cell transfusion practice in elective orthopedic surgery: a multicenter cohort study. Transfusion. 2010;50:2117-24.

3. Stanworth SJ, Cockburn HAC, Boralessa H, Contreras M. Which groups of patients are transfused? A study of red cell usage in London and southeast England. Vox Sang. 2002;83:352-7.

4. Jans O, Kehlet H, Hussain Z, Johansson PI. Transfusion practice in hip arthroplasty - a nationwide study. Vox Sang. 2011;100:374-80.

5. Browne JA, Adib F, Brown TE, Novicoff WM. Transfusion rates are increasing following total hip arthroplasty: risk factors and outcomes. J Arthroplasty. 2013;28 Suppl 8:34-7.

6. Spiess BD. Transfusion of blood products affects outcome in cardiac surgery. Semin Cardiothor Vasc Anesth. 2004;8:267-81.

7. Rawn J. The silent risks of blood transfusion. Curr Opin Anaesth. 2008;21:664-8.

8. Surgenor SD, Kramer RS, Olmstead EM, Ross CS, Sellke FW, Likosky DS, et al The association of perioperative red blood cell transfusions and decreased long-term survival after cardiac surgery. Anesth Analg. 2009;108:1741-6.

9. Koch CG, Li L, Duncan Al, Mihaljevic T, Cosgrove DM, Loop FD, et al. Morbidity and mortality risk associated with red blood cell and blood-component transfusion in isolated coronary artery bypass grafting. Crit Care Med. 2006;34:1608-16.

10. Perisanidis C, Mittlböck M, Dettke M, Schopper C, Schoppmann A, Kostakis GC, et al. Identifying risk factors for allogenic blood transfusion in oral and oropharyngeal cancer surgery with free flap reconstruction. J Oral Maxillofac Surg. 2013;71:798-804.

11. Park JH, Rasouli MR, Mortazavi SMJ, Tokarski AT, Maltenfort MG, Parvizi J. Predictors of perioperative blood loss in total joint arthroplasty. J Bone Joint Surg Am. 2013;95:1777-83.

12. Brecher ME, Monk T, Goodnough LT. A standardized method for calculating blood loss. Transfusion. 1997;37:1070-4.

13. Sehat KR, Evans RL, Newman JH. Hidden blood loss following hip and knee arthroplasty: correct management of blood loss should take hidden loss into account. J Bone Joint Surg (Br). 2004;86:561-5.

14. Ledin H, Aspenberg P, Good L. Tourniquet use in total knee replacement does not improve fixation, but appears to reduce final range of motion. Acta Orthop. 2012:83:499-503. 
15. Tetro AM, Rudan JF. The effects of a pneumatic tourniquet on blood loss in total knee arthroplasty. Can J Surg. 2001;44:33-8.

16. Liu X, Zhang $X$, Chen Y, Wang Q, Jiang Y, Zeng B. Hidden blood loss after total hip arthroplasty. J Arthroplasty. 2011;26:1100-5.

17. Karthik S, Grayson AD, McCarron EE, Pullan DM, Desmond MJ. Reexploration for bleeding after coronary artery bypass surgery: risk factors, outcomes, and the effect of time delay. Ann Thorac Surg. 2004;78:527-34.

18. Prasad N, Padmanabhan V, Mullaji A. Blood loss in total knee arthroplasty: an analysis of risk factors. Int Orthop. 2007;31:39-44.

19. Hrnack SA, Skeen $N, X u T$, Rosenstein AD. Correlation of body mass index and blood loss during total knee and total hip arthroplasty. Am J Orthop. 2012;41:467-71.

20. Bowditch MG, Villar RN. Do obese patients bleed more? A prospective study of blood loss at total hip replacement. Ann R Coll Surg Engl. 1999:81:198-200.

21. Walsh M, Preston C, Bong M, Patel V, Di Cesare PE. Relative risk factors for requirement of blood transfusion after total hip arthroplasty. J Arthroplasty. 2007;22:1162-7.

22. Bong MR, Patel V, Chang E, Issack PS, Hebert R, Di Cesare PE. Risks associated with blood transfusion after total knee arthroplasty. I Arthroplasty. 2004;19:281-7.

23. Capraro L. Transfusion practices in primary total joint replacements in Finland. Vox Sang. 1998;75:1-6.

24. Borghi B, Casati A. Incidence and risk factors for allogenic blood transfusion during major joint replacement using an integrated autotransfusion regimen. Eur J Anaesthesiol. 2000;17:411-7.

25. So-Osman C, Nelissen R, Brand R, Faber F, Slaa RT, Stiggelbout A, et al. The impact of a restrictive transfusion trigger on post-operative complication rate and well-being following elective orthopaedic surgery: a post-hoc analysis of a randomised study. Blood Transfus. 2013;11:289-95.

26. Robinson PM, Obi N, Harison T, Jeffery J. Changing transfusion practice in total hip arthroplasty: observational study of the reduction of blood use over 6 years. Orthopedics. 2012;35:e1586-91.

27. Hatzidakis AM, Mendlick RM, McKillip T, Reddy RL, Garvin KL. Preoperative autologous donation for total joint arthroplasty: an analysis of risk factors for allogenic transfusion. J Bone Joint Surg Am. 2000;82:89-100.

28. Barr PJ, Donnelly M, Cardwell C, Alam SS, Morris K, Parker M, et al. Drivers of transfusion decision making and quality of the evidence in orthopedic surgery: a systematic review of the literature. Transfus Med Rev. 2011;25:304-16

29. Guerin S, Collins C, Kapoor H, McClean I, Collins D. Blood transfusion requirement prediction in patients undergoing primary total hip and knee arthroplasty. Transfus Med. 2007;17:37-43.

30. Mesa-Ramos F, Mesa-Ramos M, Maquieira-Canosa C, Carpintero P. Predictors for blood transfusion following total knee arthroplasty: a prospective randomised study. Acta Orthop Belg. 2008;74:83-9.

31. Spahn DR. Anemia and patient blood management in hip and knee surgery: a systematic review of the literature. Anesthesiology. 2010:113:482-95.

32. Martinez V, Monsaingeon-Lion A, Cherif $K$, Judet T, Chauvin M, Fletcher D. Transfusion strategy for primary knee and hip arthroplasty: impact of an algorithm to lower transfusion rates and hospital costs. Br J Anaesth 2007:99:794-800.

33. Carless PA, Henry DA, Moxey AJ, O'Connell D, Brown T, Fergusson DA. Cell salvage for minimising perioperative allogeneic blood transfusion. Cochrane Database Syst Rev. 2010;14(4):CD001888.

34. Boralessa H, Goldhill DR, Tucker K, Mortimer AJ, Grant-Casey J. National comparative audit of blood use in elective primary unilateral total hip replacement surgery in the UK. Ann R Coll Surg Engl. 2009;91:599-605.

35. Ker K, Edwards P, Perel P, Shakur H, Roberts I. Effect of tranexamic acid on surgical bleeding: systematic review and cumulative meta-analysis. BMJ. 2012;344:e3054.

\section{Submit your next manuscript to BioMed Central and take full advantage of:}

- Convenient online submission

- Thorough peer review

- No space constraints or color figure charges

- Immediate publication on acceptance

- Inclusion in PubMed, CAS, Scopus and Google Scholar

- Research which is freely available for redistribution 